\title{
Electromagnetic Simulation of New Tunable Guide Polarizers with Diaphragms and Pins
}

\author{
Stepan Piltyay', Andrew Bulashenko', Vadym Shuliak1, and Oleksandr Bulashenko² \\ ${ }^{1}$ Department of Theoretical Foundations of Radio Engineering, National Technical University of Ukraine "Igor Sikorsky Kyiv Polytechnic Institute", \\ Kyiv, Ukraine \\ ${ }^{2}$ Electromechanical Department, Ivan Kozhedub Shostka Professional College of Sumy State University, Shostka, Ukraine \\ Corresponding author: Stepan Piltyay (e-mail: crosspolar@ukr.net).
}

\begin{abstract}
In this article we present the results of electromagnetic simulation, development and optimization of a guide polarizer with a diaphragm and pins. An original mathematical model was obtained using the wave matrix approach for a guide polarizer with one diaphragm and two pairs of pins. The discontinuity elements were modeled as inductive or capacitive conductivities for two kinds of linear perpendicular polarizations of the electromagnetic waves. The theoretical model is based on wave scattering and transfer matrices. The total matrix of a polarizer was developed using wave matrices of transmission of separate elements of a polarizer's structure. Using elements of the general S-parameters the electromagnetic characteristics of a considered polarizer were obtained. In order to test the performance of a suggested mathematical model, it was simulated in a software based on the finite elements method in the frequency domain. The presented design of a polarizer is adjustable due to possibility of mechanical tuning of the heights of applied pins. Considered guide polarizer with one diaphragm and two pairs of pins provides a reflection coefficient of less than 0.36 and a transmission coefficient of more than 0.93 for both linear perpendicularly polarized modes. Therefore, a new theoretical technique was developed in the research for fast electromagnetic simulation of wave matrix elements of a guide polarizers with diaphragms and pins. Developed simulation approach can also be widely used for the development of new tunable guide filters, polarizers, rotators and other microwave components with diaphragms and pins.
\end{abstract}

INDEX TERMS electromagnetic simulation; microwave engineering; waveguide components; electromagnetics; waveguide polarizer; microwave passive devices; wave matrix; polarization.

\section{INTRODUCTION}

$\mathbf{T}$ HE modernization of state-of-the-art radio engineering systems has contributed to the emergence of new radar and satellite telecommunication systems, metrological equipment, navigation systems and mobile communication systems. Ku-band is widely used in satellite television systems. One of the main reasons is the shorter electromagnetic wavelengths, which allow the reception of signals by parabolic antennas of small sizes [1]. Such systems are applied in radio engineering systems with polarization signal processing [2-11]. The development of these systems expanded information capacity of communication channels by the use of modern microwave filters, orthomode converters and waveguide polarizers. In particular, modern telecommunication systems apply various adjustable waveguide filters and other components [12-19]. The operating frequency range is regulated by means of pins. Orthomode transducers support separation of the transmitted and received orthogonal signals for the same antenna system [20-25]. They also direct the transmitted wave's energy to an antenna and prevent the transmission to the sensitive receivers in radars.

The function of a microwave waveguide polarizer is to convert electromagnetic waves from orthogonal circular polarizations into the waves with perpendicular linear polarizations. A polarizer can be designed and manufactured based on circular [26-31], coaxial [32-34] or rectangular/square waveguides [35-41]. The phase differential between linear polarizations of this device should be 90 degrees, therefore its stabilization in the operating frequency range is an actual problem.

Coaxial polarizers [32-34] are used in dual-band radio engineering systems to transform the polarizations of signals in lower frequency band of two separate operating frequency bands. To create broadband and ultra-wideband waveguide polarizers the ridges are introduced into the structure [42-47]. The basic drawback of such devices is their sophisticated design and complicated mathematical methods, which are required for their analysis [48-56].

Waveguide septum polarizers are also frequently used [57-63]. They represent a specially formed phase-shifting structure created from a conductive metal septum with steps. The advantages of septum polarizers are broadband operation, good ellipticity coefficient of about $1 \mathrm{~dB}$, ease of installation in a waveguide, versatility due to the possibility of choosing the type of polarization by installing a septum 
in the waveguide and an acceptable cost for the consumer. It is especially important to provide resistance to fading and polarization mismatch for $5 \mathrm{G}$ wireless systems [64-70].

The resonant features of the pins limit the application of waveguide polarizers with them [71-83], since this design has a lower bandwidth. In addition, at the boundaries of the operating frequency range the ellipticity coefficient takes large values, which is undesirable effect in modern satellite communication systems.

The main advantage of a waveguide polarizer with diaphragms over polarizers of other types is the ability to provide the most broadband mode of operation with good electromagnetic characteristics. A positive feature of using pin polarizers is the ability to tune them [79-83]. On the contrary, waveguide polarizers with diaphragms are not adjustable devices. Consequently, it is proposed to combine wideband diaphragm structures with adjustable pins. Thus, in this research we will introduce several pins into the design of a guide iris polarizer to enable its tuning.

Therefore, in this research we will solve an actual problem of the development of new adjustable square waveguide polarizers applying diaphragm and pins, which provides the effective electromagnetic characteristics in the operating frequency band.

\section{THEORETICAL MODELING OF WAVEGUIDE POLARIZERS WITH DIAPHRAGM AND PINS}

The mathematical calculation and initial estimation of electromagnetic characteristics of a waveguide polarizers with diaphragms is usually carried out by means of the theory of equivalent microwave circuits [84]. It was implemented before using wave scattering and transmission matrices in [85-87]. This approach makes it possible to express the basic values of the polarizer through the elements of the generalized transmission or scattering matrix. Let's use it to create our mathematical model.

The inner geometrical configuration of a developed and analyzed polarization converter containing a diaphragm and four pins is presented in Fig. 1.

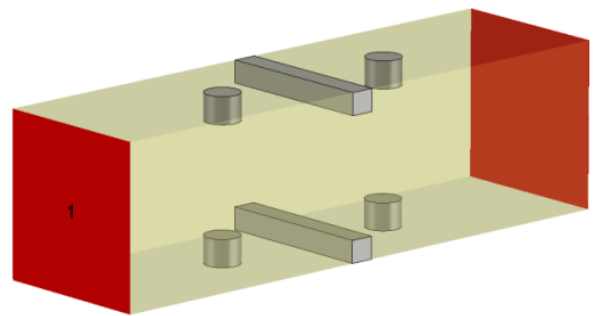

FIGURE 1. General view of a waveguide polarizer with diaphragm and pins.

The design of this polarizer contains four identical pins and one diaphragm. Each pair of pins is located symmetrically with respect to the diaphragm, which in turn is located in the center of the waveguide section.

For the theoretical analysis we will apply a single-wave approach using the wave matrix technique [85-87]. The equivalent networks of a considered waveguide polarizer for the cases of capacitive and inductive diaphragms are given in Fig. 2a and 2b, respectively.

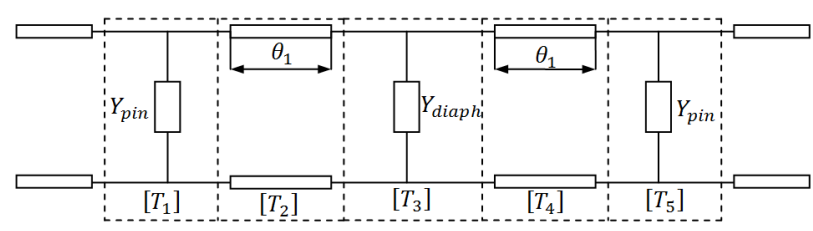

(a)

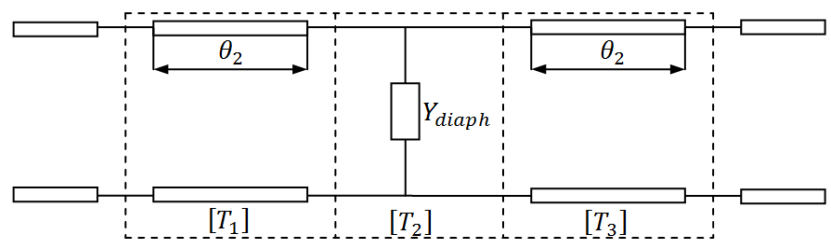

(b)

FIGURE 2. Equivalent networks of a polarizer with a diaphragm of capacitive type (a) and inductive type (b)

The equivalent conductivities of diaphragm in a square waveguide are determined by the following formulas [85]:

$$
\begin{aligned}
b_{C} & \cong \frac{4 b}{\lambda_{g}} \cdot \ln \left[\operatorname{cosec}\left(\frac{\pi \cdot d}{2 a}\right)\right], \\
b_{L} & \cong-\frac{\lambda_{g}}{a} \cdot\left[\operatorname{ctg}\left(\frac{\pi \cdot d}{2 a}\right)\right]^{2},
\end{aligned}
$$

where $a$ is the width of walls of a square waveguide; $d$ is the width of spacing or diaphragm window; $\lambda_{\mathrm{g}}$ is the length of fundamental wave in a considered square guide.

Two equivalent circuits have uniform sections of the transmission line with electrical length $\theta$, which is calculated by the formula:

$$
\theta=\frac{2 \pi \cdot l}{\lambda_{g}}
$$

The wavelength in a square waveguide is determined as follows $[7,8]$ :

$$
\lambda_{g}=\frac{\lambda_{0}}{\sqrt{1-\left(\frac{\lambda_{0}}{2 a}\right)^{2}}}
$$

where $\lambda_{0}$ is the length of electromagnetic wave in vacuum, $2 a$ is the cutoff length of the fundamental TE 10 wave in a square guide.

The equivalent conductivity of the pin in a rectangular waveguide is defined by the following expression [88]:

$$
Y_{\text {pin }}=\frac{j \pi \lambda_{0} \lambda_{g}(1-\cos \varphi)^{2}}{a^{2} k(a-r)(2+\cos (2 \varphi))-\ln (a / r) \sin (2 \varphi)},
$$

where $\varphi=k l_{p i n}, l_{p i n}$ is pin's height, $k$ stands for the wave number, $r$ designates radius of a cylindrical pin.

For the vertically polarized fundamental mode $\mathrm{TE}_{10}$ the equivalent circuit of a square waveguide can be divided into five simple two-port circuits (Fig. 2, a). They include a twoport circuit that is equivalent to a capacitive diaphragm, two circuits that are equivalent to a capacitive pin, and two circuits of regular transmission line segments. These circuits are described by the transfer matrices [10]: 


$$
\begin{gathered}
{\left[T_{1}\right]=\left[T_{5}\right]=\left[\begin{array}{ll}
T_{11} & T_{12} \\
T_{21} & T_{22}
\end{array}\right]=\left[\begin{array}{cc}
\frac{2+Y_{\text {pin }}}{2} & \frac{Y_{\text {pin }}}{2} \\
-\frac{Y_{\text {pin }}}{2} & \frac{2-Y_{\text {pin }}}{2}
\end{array}\right] ;} \\
{\left[T_{2}\right]=\left[T_{4}\right]=\left[\begin{array}{cc}
e^{j \theta_{1}} & 0 \\
0 & e^{-j \theta_{1}}
\end{array}\right] ;} \\
{\left[T_{3}\right]=\left[\begin{array}{cc}
T_{11}^{\prime} & T_{12}^{\prime} \\
T_{21}^{\prime} & T_{22}^{\prime}
\end{array}\right]=\left[\begin{array}{cc}
\frac{2+Y_{\text {diaph }}}{2} & \frac{Y_{\text {diaph }}}{2} \\
-\frac{Y_{\text {diaph }}}{2} & \frac{2-Y_{\text {diaph }}}{2}
\end{array}\right],}
\end{gathered}
$$

where $Y_{\text {pin }}$ and $Y_{\text {diaph }}$ denote the conductivity of the pin and diaphragm, respectively; $\theta_{1}$ is an electric length of the equivalent transmission line.

According to the theory of wave matrices, general wave T-matrix of the waveguide polarizer is given as the product of partial transfer matrices $[7,8]$ :

$$
\left[T_{\Sigma}^{\mathrm{vert} \text { pol }}\right]=\left[T_{1}\right] \cdot\left[T_{2}\right] \cdot\left[T_{3}\right] \cdot\left[T_{4}\right] \cdot\left[T_{5}\right]=\left[\begin{array}{ll}
T_{\sum 11} & T_{\sum 12} \\
T_{\sum 21} & T_{\sum 22}
\end{array}\right] .
$$

For propagation of the main electromagnetic wave polarized in horizontal direction the equivalent circuit of the polarizer can be divided into three simple two-port circuits (Fig. 2b). They include a two-port inductive diaphragm equivalent circuit and two two-port transmission line section circuits. In this case the influence of an inductive pins is neglected. The equivalent circuits are described by the following transfer matrices:

$$
\begin{gathered}
{\left[T_{1}\right]=\left[T_{3}\right]=\left[\begin{array}{cc}
e^{j \theta_{2}} & 0 \\
0 & e^{-j \theta_{2}}
\end{array}\right] ;} \\
{\left[T_{2}\right]=\left[\begin{array}{cc}
T_{11}^{\prime} & T_{12}^{\prime} \\
T_{21}^{\prime} & T_{22}^{\prime}
\end{array}\right]=\left[\begin{array}{cc}
\frac{2+Y_{\text {diaph }}}{2} & \frac{Y_{\text {diaph }}}{2} \\
-\frac{Y_{\text {diaph }}}{2} & \frac{2-Y_{\text {diaph }}}{2}
\end{array}\right],}
\end{gathered}
$$

where $\theta_{2}$ stands for an electric length of the equivalent transmission line.

Then the general wave transmission matrix for the fundamental electromagnetic mode with horizontal linear polarization is determined as follows:

$$
\left[T_{\Sigma}^{\text {hor pol }}\right]=\left[T_{1}\right] \cdot\left[T_{2}\right] \cdot\left[T_{3}\right]=\left[\begin{array}{ll}
T_{\Sigma 11} & T_{\sum 12} \\
T_{\sum 21} & T_{\sum 22}
\end{array}\right] .
$$

The mathematical relation between wave T-matrix and S-matrix is determined by the following formula [84-86]:

$$
\left[S_{\Sigma}\right]=\left[\begin{array}{ll}
S_{\sum 11} & S_{\Sigma 12} \\
S_{\sum 21} & S_{\Sigma 22}
\end{array}\right]=\frac{1}{T_{\Sigma 11}}\left[\begin{array}{cc}
T_{\sum 21} & |T| \\
1 & -T_{\Sigma 12}
\end{array}\right],
$$

where $|T|$ denotes the determinant of transfer matrix $\left[T_{\Sigma}\right]$ calculated using (9) and (12).

From the formula (13) we obtain expressions for the reflection factor $S_{\sum 11}$ and transfer factor $S_{\sum 21}$ of the analyzed waveguide polarizer $[7,8]$ as follows:

$$
S_{\Sigma 11}=\frac{\mathrm{T}_{\sum 21}}{\mathrm{~T}_{\Sigma 11}} ; \quad S_{\sum 21}=\frac{1}{\mathrm{~T}_{\Sigma 11}} .
$$

Therefore, the mathematical model of a guide polarizer with diaphragm and pins was developed based on the wave matrix method. In the following section we will apply created mathematical model for analysis of electromagnetic characteristics and development of a guide polarizer.

\section{RESULTS OF MATHEMATICAL AND NUMERICAL SIMULATION OF ELECTROMAGNETIC PERFORMANCE}

This section presents the results of calculations of the reflection and transfer factors of the waveguide polarizer obtained using the developed mathematical model for the satellite operating frequency range from 11.7 to $12.5 \mathrm{GHz}$.

Fig. 3 indicates that module of the reflection coefficient of the developed mathematical model of a waveguide polarizer for both fundamental modes $\mathrm{TE}_{01}$ and $\mathrm{TE}_{10}$ is less than 0.37 in the frequency range from 11.7 $\mathrm{GHz}$ to $12.5 \mathrm{GHz}$. The lowest magnitude of the absolute value of the reflection factor of the polarizer is 0.06 at a frequency of $11.7 \mathrm{GHz}$.

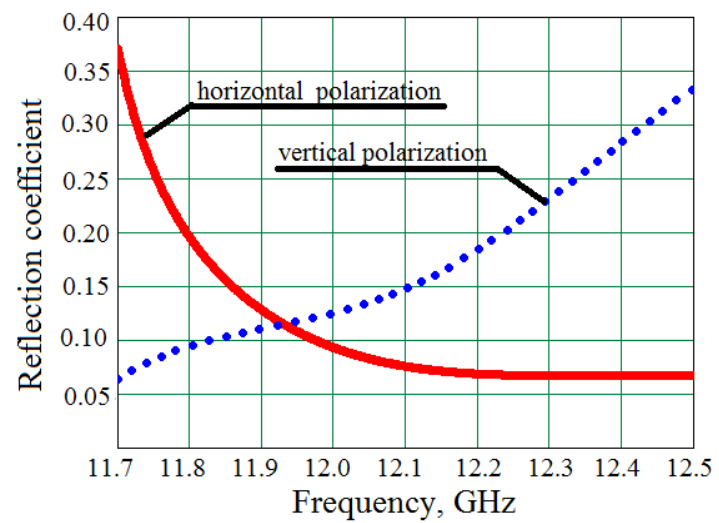

FIGURE 3. Reflection coefficients simulated by a mathematical model.

Fig. 4 demonstrates that module of the transmission coefficient of developed mathematical waveguide polarizer for both fundamental modes $\mathrm{TE}_{01}$ and $\mathrm{TE}_{10}$ is greater than 0.937 in the DBS-band from $11.7 \mathrm{GHz}$ to 12.5 GHz. The highest magnitude of the absolute value of the reflection factor of the polarizer is 0.994 at a frequency of $12.05 \mathrm{GHz}$.

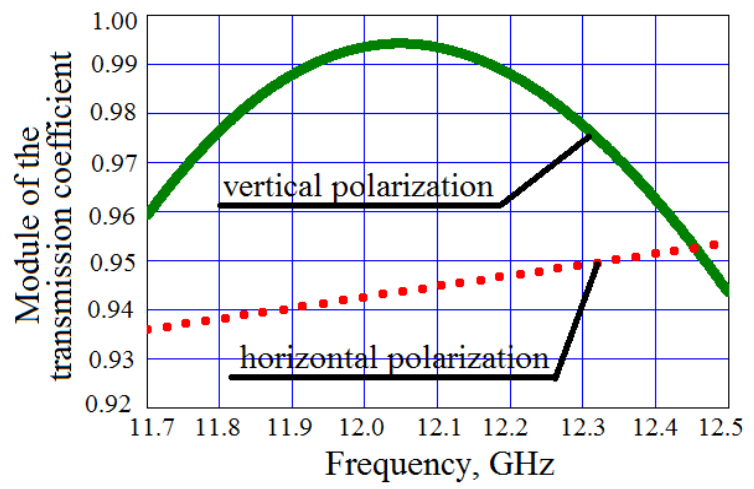

FIGURE 4. Dependences of module of transmission coefficients on frequency for both linear polarizations calculated by the mathematical model. 
Fig. 5 shows the dependences of conductivity on frequency for the pin of developed polarizer for different heights. Due to the inaccuracy of manufacturing, the characteristics of a real polarizer would differ from those calculated using a mathematical model. They can be adjusted by changing the height of the pins. In Fig. 5 it is seen that with an increase in the height of the pin, the maximum value of the conductivity of the pin increases.

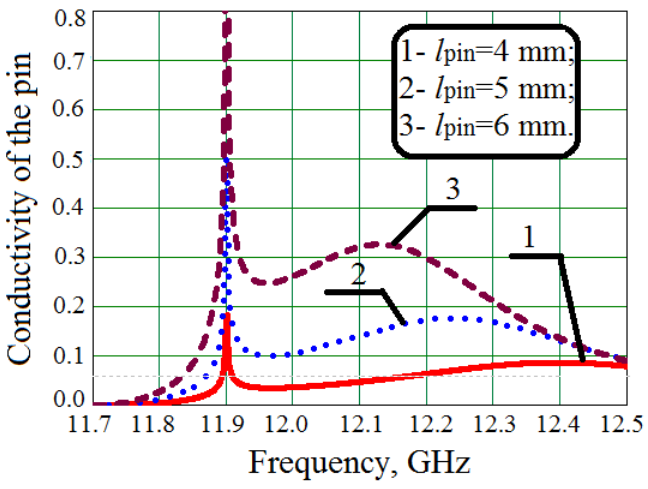

FIGURE 5. Simulated conductivity of the pin for different heights.

Below we present the results of numerical modeling applying the finite element technique in the frequency domain $[89,90]$. As a result, graphical dependences of the reflection and transfer factors of the polarizer in the operating frequency range were obtained.

Fig. 6 presents the dependences of module of reflection coefficient on frequency for both polarizations.

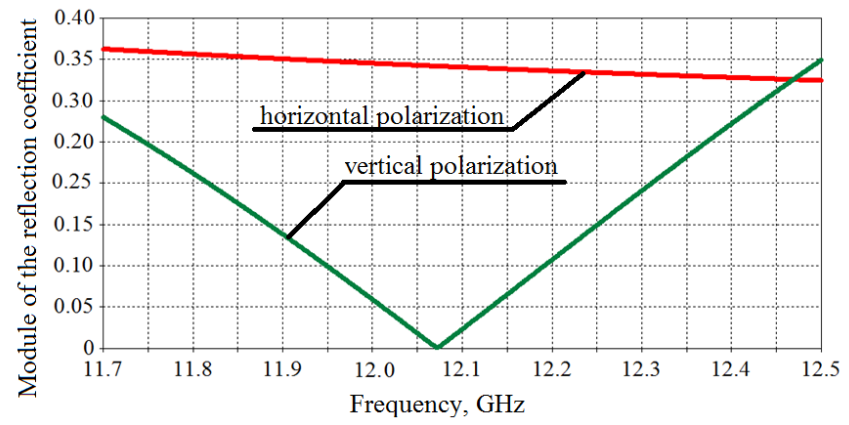

FIGURE 6. Dependences of module of the reflection coefficient on frequency for horizontal and vertical polarizations calculated by the numerical model.

Fig. 7 presents the dependences of phase of reflection coefficient on frequency for both polarizations.

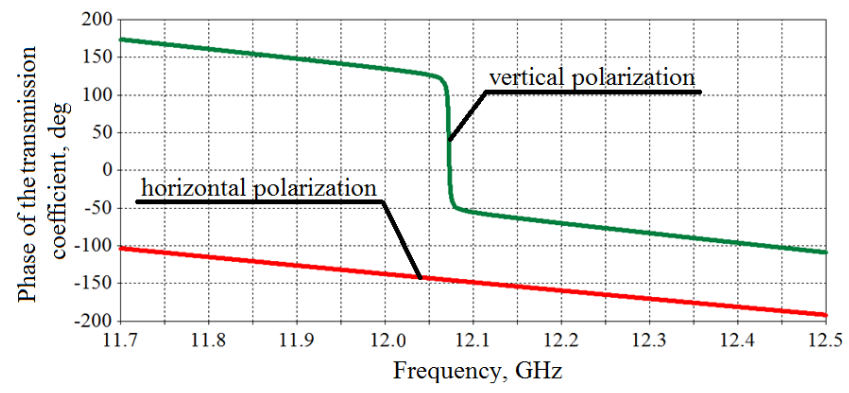

FIGURE 7. Dependences of phase of the reflection coefficient on frequency for horizontal and vertical polarizations calculated by the numerical model.
Fig. 6 demonstrates that module of the reflection coefficient of developed waveguide polarizer for both fundamental modes $\mathrm{TE}_{01}$ and $\mathrm{TE}_{10}$ is less than 0.36 in the DBS-band from $11.7 \mathrm{GHz}$ to $12.5 \mathrm{GHz}$. The lowest magnitude of the modulus of the reflection coefficient of the polarizer is 0 at a frequency of $12.06 \mathrm{GHz}$.

Fig. 8 and Fig. 9 present the dependences absolute value of the transmission coefficient and its argument on frequency for the developed polarizer.

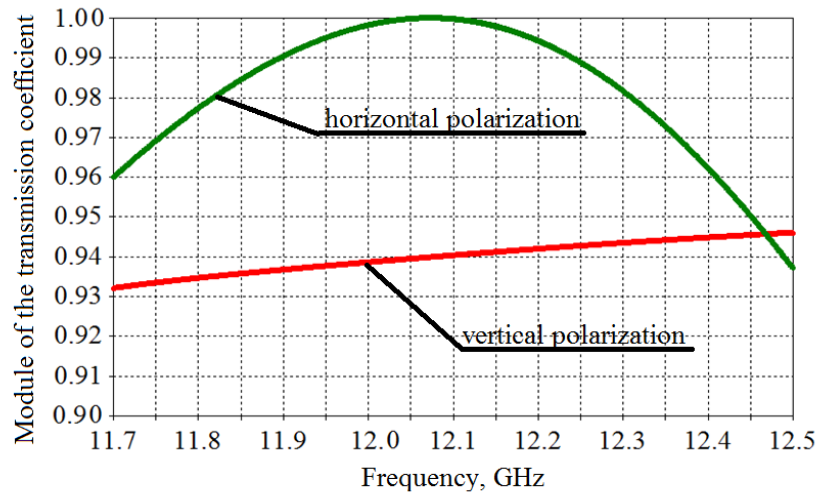

FIGURE 8. Dependences of module of transmission coefficients on frequency for horizontal and vertical polarizations calculated by the numerical model.

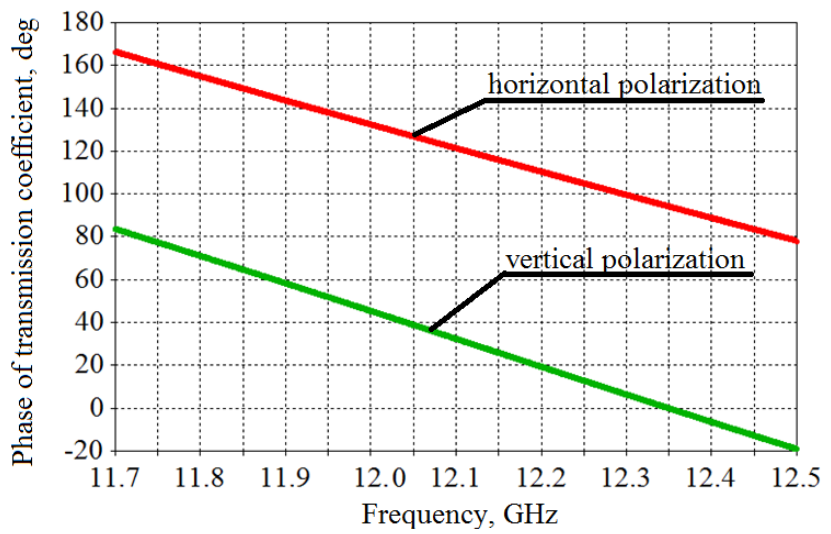

FIGURE 9. Dependences of phase of the transmission coefficient on frequency for horizontal and vertical polarizations calculated by the numerical model.

In Fig. 8 it can be seen that in the operating frequency range of $11.7-12.5 \mathrm{GHz}$ the modulus of the transmission coefficient reaches a maximum value of 1.0 at a frequency of $12.06 \mathrm{GHz}$. Fig. 9 shows that the phase for horizontal polarization decreases from $165^{\circ}$ to $78^{\circ}$, and for vertical polarization decreases from $78^{\circ}$ to $-20^{\circ}$. The minimum value of the modulus of the transmission coefficient of the waveguide polarizer is 0.931 at a frequency of $11.7 \mathrm{GHz}$.

Fig. 10 presents the dependences module of the cross polarization transformation on frequency for the developed polarizer. This indicator demonstrates the process of converting vertical polarization to horizontal and vice versa. 


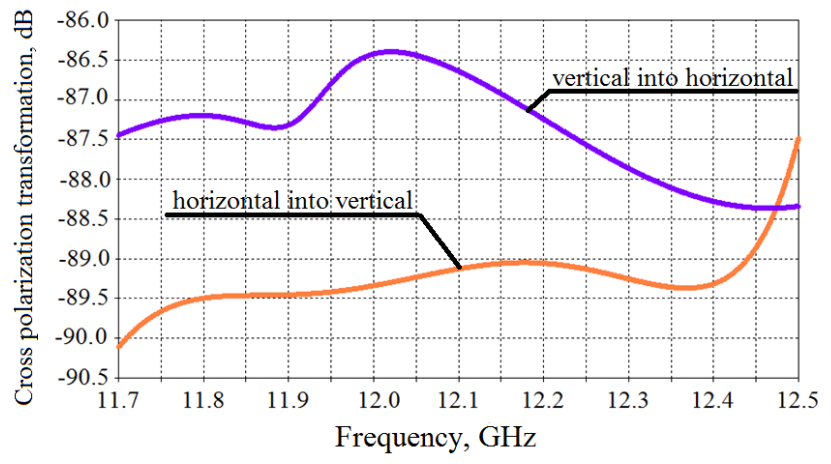

FIGURE 10. Dependences of module of cross polarization transformation coefficients on frequency for both polarizations calculated by numerical model.

In Fig. 10 it can be seen that in the operating frequency range of $11.7-12.5 \mathrm{GHz}$, the modulus of the cross polarization transformation reaches a maximum value of $-86.5 \mathrm{~dB}$ at a frequency of $12.02 \mathrm{GHz}$. The minimum value of the cross polarization transformation by vertical polarization is $-88.3 \mathrm{~dB}$ at $12.47 \mathrm{GHz}$. The minimum value of the cross polarization transformation by vertical polarization is $-91.1 \mathrm{~dB}$ at $11.7 \mathrm{GHz}$ and the maximum value of the cross polarization transformation by vertical polarization is $-87.5 \mathrm{~dB}$ at $12.5 \mathrm{GHz}$.

Table 1 presents main electromagnetic parameters of the optimized guide polarizer with a diaphragm and 4 pins in the operating band 11.7-12.5 GHz. These results were obtained by the mathematical and numerical models.

TABLE I. COMPARISON OF THE ELECTROMAGNETIC PARAMETERS CALCULATED BY TWO METHODS FOR A WAVEGUIDE POLARIZER WITH A DIAPHRAGM AND PINS

\begin{tabular}{ccc}
\hline \hline $\begin{array}{c}\text { Type of } \\
\text { model }\end{array}$ & $\begin{array}{c}\text { Maximal level of } \\
\text { reflection coefficient }\end{array}$ & $\begin{array}{c}\text { Minimal level of } \\
\text { transmission coefficient }\end{array}$ \\
\hline $\begin{array}{c}\text { Mathematical } \\
\text { model }\end{array}$ & 0.37 & 0.937 \\
$\begin{array}{c}\text { Numerical } \\
\text { method }\end{array}$ & 0.36 & 0.932 \\
\hline \hline
\end{tabular}

Therefore, we can conclude from Table 1 that all the maximal levels of the reflection coefficient and minimal levels of the transmission coefficient almost coincided for both theoretical methods. This proves the correctness of the developed electromagnetic model of a waveguide polarizer with a diaphragm and pins.

\section{CONCLUSIONS}

In this paper a new mathematical model of a polarizer based on a square waveguide with a diaphragm and four pins was developed. The proposed design of a polarizer provides the possibility to adjust the electromagnetic characteristics of the polarizer by changing the length of the pins. Using the developed mathematical model, the total scattering matrix elements were obtained and optimized in the operating satellite DBS-band. The waveguide polarizer maintains modulus of the reflection coefficient less than 0.37 . The modulus of the transmission coefficient is higher than 0.93 for both perpendicular linear polarizations. The cross polarization transformation reaches a maximum value of $-86.5 \mathrm{~dB}$ at a frequency of $12.02 \mathrm{GHz}$ and reaches a minimum value of $-91.1 \mathrm{~dB}$ at the frequency of $11.7 \mathrm{GHz}$.

The developed theoretical model can be used to develop and optimize scattering matrix elements of waveguide polarizers and other components with diaphragms and pins. Next researches need to focus on the creation of mathematical models with a larger number of diaphragms and pins to ensure better performance of the polarizer. The proposed waveguide structure can also be suggested to create new adjustable waveguide filters and phase shifters for various radio engineering applications.

\section{REFERENCES}

[1] W. L. Stutzman, G.A. Thiele, Antenna Theory and Design. New Jersey, USA: John Wiley and Sons, 2013.

[2] D.M. Pozar, Microwave Engineering. John Wiley and Sons, 2012.

[3] S. Gao, F. Zhu, Circular polarized Antenna Theory and Design. Chichester, USA: John Wiley and Sons, 2013.

[4] W. L. Stutzman, Polarization in Electromagnetic Systems. Norwood, MA, USA: Artech House, 2018.

[5] Y. Huang, K. Boyle, Antennas: From Theory to Practice. Chichester, USA: John Wiley and Sons, 2008.

[6] K. Chang, Encyclopedia of RF and Microwave Engineering. New Jersey, USA: John Wiley and Sons, 2005.

[7] R.E. Collin, Foundations for Microwave Engineering. New Jersey, USA: John Wiley and Sons, 2001.

[8] R. Sorrentino, G. Bianchi, Microwave and RF Engineering. New Jersey, USA: John Wiley and Sons, 2010.

[9] F. Dubrovka, et al., "Circularly polarised X-band H11- and H21modes antenna feed for monopulse autotracking ground station", IEEE Ukrainian Microwave Week, Kharkiv, Ukraine, September 2020, pp. 196-202. DOI: 10.1109/UkrMW49653.2020.9252600.

[10] S.A. Maas, Practical microwave circuits. USA: Artech House, 2014.

[11] J. A. Ruiz-Cruz, et al., "Waveguide antenna feeders with integrated reconfigurable dual circular polarization", IEEE Transactions on Microwave Theory and Techniques, vol. 59, no. 12, pp. 3365-3374, December 2011. DOI: 10.1109/TMTT.2011.2170581.

[12] A.A. Kirilenko, et al., "A waveguide iris with a vertical step-shaped slot and a bandpass filter built around it", Telecommunications and Radio Engineering, vol. 72, no 7, pp. 567-579, 2013.

[13] A.A. Kirilenko, et al., "Compact septum polarizer with a circular output waveguide", IEEE 5th Int. Kharkov Symposium on Physics and Engineering of Microwaves, Millimeter, and Submillimeter Waves, Kharkov, Ukraine, 2004. DOI: 10.1109/MSMW.2004.1346088.

[14] I. Kim, et al., "Revisiting stepped septum circular polarizer using full-wave simulations", IEEE Int. Symp. on Antennas \& Propagation, Spokane, USA, 2011. DOI: 10.1109/APS.2011.5996425.

[15] J. Kim, et al., "Triangular-shaped stepped septum polarizer for satellite communication", IEEE Int. Symp. on Antennas \& Propagat., USA, 2001, pp. 854-857. DOI: 10.1109/APS.2011.5996409.

[16] A. Mediavilla, et al., "Compact quasi-octave bandwidth phase matched $\mathrm{K} / \mathrm{Ka}$ antenna feed subsystem for dual RHCP/LHCP polarization”, European Microwave Conf., Amsterdam, Netherlands, 2011, pp. 1099-1102. DOI: 10.23919/EuMC.2012.6459338.

[17] W. Zhong, B. Li, Q. Fan, and Z. Shen, "X-band Compact Septum Polarizer Design", IEEE Int. Conf. on Microwave Technology and Computational Electromagnetics, Beijing, China, 2011, pp. 167-170. DOI: 10.1109/ICMTCE.2011.5915191.

[18] X. Wang, et al., "Novel square/rectangle waveguide septum polarizer", IEEE Int. Conference on Ubiquitous Wireless Broadband, Nanjing, China, 2016. DOI: 10.1109/ICUWB.2016.7790510.

[19] F.F. Dubrovka, et al, "Optimum septum polarizer design for various fractional bandwidth", Radioelectronics and Communications Systems, vol. 63, no. 1, pp. 15-23, 2020. DOI: $10.3103 / \mathrm{S} 0735272720010021$. 
[20] C.A. Leal-Sevillano, et al., "A $225 \mathrm{GHz}$ circular polarization waveguide duplexer based on a septum orthomode transducer polarizer", IEEE Trans. Terahertz Science and Technology, Vol 3, no 5, pp. 574-583, 2020. DOI: 10.1109/TTHZ.2013.2264317.

[21] F.F. Dubrovka, et al., "A high performance ultrawideband orthomode transducer and a dual-polarized quad-ridged horn antenna based on it", VIII Int. Conf. on Antenna Theory and Techniques, Kyiv, Ukraine, 2011, pp. 176-178. DOI: 10.1109/ICATT.2011.6170737.

[22] S. I. Piltyay, "High performance extended C-band 3.4-4.8 GHz dual circular polarization feed system", XI International Conference on Antenna Theory and Techniques (ICATT), Kyiv, Ukraine, May 2017, pp. 284-287. DOI: 10.1109/ICATT.2017.7972644.

[23] F. F. Dubrovka, et al., "Novel high performance coherent dualwideband orthomode transducer for coaxial horn feeds", XI Int. Conference on Antenna Theory and Techniques, Kyiv, Ukraine, May 2017, pp. 277-280. DOI: 10.1109/ICATT.2017.7972642.

[24] S. I. Piltyay, "Enhanced C-band coaxial orthomode transducer", Visnyk NTUU KPI Seriia - Radiotekhnika, Radioaparatobuduvannia, Vol. 58, pp. 35-42, 2014. DOI: 10.20535/RADAP.2014.58.35-42.

[25] C. Granet, et al., "The designing, manufacturing, and testing of a dual-band feed system for the Parkes radio telescope", IEEE Antennas and Propagation Magazine, Vol. 47, no 3, pp. 13-19, 2005.

[26] G. Virone, et al., "Optimum-Iris-Set Concept for Waveguide Polarizers", IEEE Microwave and Wireless Compon. Letters, Vol. 17, no 3, pp. 202-204, 2007. DOI: 10.1109/LMWC.2006.890474.

[27] V. Naydenko, et al., "Evolution of radiopulses radiated by Hertz's dipole in vacuum", 12-th International Conference on Mathematical Methods in Electromagnetic Theory (MMET), Odesa, Ukraine, July 2008, pp. 294-297. DOI: 10.1109/MMET.2008.4580972.

[28] A.A. Kirilenko, et al., "A tunable compact polarizer in a circular waveguide", IEEE Transactions on Microwave Theory and Techniques, Vol. 67, no 2, pp. 592-596, 2019.

[29] Yu. Tikhov, "Comparison of two kinds of Ka-band circular polarisers for use in a gyro-travelling wave amplifier", IET Microwaves, Antennas and Propagation, Vol. 10, no 2, pp. 147-151, 2016. DOI: 10.1049/iet-map.2015.0292.

[30] G. Bertin, et al., "Full-wave design and optimization of circular waveguide polarizers with elliptical irises", IEEE Transactions on Microwave Theory and Techniques, Vol. 50, no 4, pp. 1077-1083, 2002. DOI: $10.1109 / 22.993409$.

[31] A. A. Kirilenko, et al., "A tunable compact polarizer in a circular waveguide", IEEE Transactions on Microwave Theory and Techniques, Vol. 67, no 2, pp. 592-596, 2019. DOI: 10.1109/TMTT.2018.2881089.

[32] F. F. Dubrovka, et al., "A novel wideband coaxial polarizer", IEEE Int. Conference on Antenna Theory and Techniques, Odesa, Ukraine, 2013, pp. 473-474. DOI: 10.1109/ICATT.2013.6650816.

[33] H. Z. Zhang, "An integrated coaxial circular-polarised OMJ/OMT for dual-band feed applications", IEEE International Antennas and Propagation Symposium Digest, Washington, Vol. 43, pp. 647-650, 2005. DOI: 10.1109/APS.2005.1551894.

[34] S. I. Piltyay, "Numerically effective basis functions in integral equation technique for sectoral coaxial ridged waveguides", 14-th International Conference on Mathematical Methods in Electromagnetic Theory (MMET), Kyiv, Ukraine, August 2012, pp. 492-495. DOI: 10.1109/MMET.2012.6331195.

[35] S. Piltyay, et al., "Analytical modeling and optimization of new $\mathrm{Ku}-$ band tunable square waveguide iris-post polarizer," International Journal of Numerical Modelling: Electronic Networks, Devices and Fields, vol. 34, no. 5, pp. 1-27, 2021. DOI: 10.1002/JNM.2890.

[36] I. Fesyuk, et al., "Waveguide polarizer for radar systems of $2 \mathrm{~cm}$ wavelength range", IEEE 3rd Ukraine Conference on Electrical and Computer Engineering, Lviv, Ukraine, August 2021.

[37] S.I. Piltyay, O. Yu. Sushko, A. V. Bulashenko, and I. V. Demchenko, "Compact Ku-band iris polarizers for satellite telecommunication systems", Telecommunications and Radio Engineering, vol. 79, no. 19, pp. 1673-1690, 2020. DOI: 10.1615/TelecomRadEng.v79.i19.10.

[38] A. Polishchuk, et al., "Compact posts-based waveguide polarizer for satellite communications and radar systems", IEEE 3rd Ukraine
Conference on Electrical and Computer Engineering, Lviv, Ukraine, August 2021.

[39] S. I. Piltyay, A. V. Bulashenko, and I. V. Demchenko, "Waveguide iris polarizers for Ku-band satellite antenna feeds", Journal of Nanoand Electronic Physics, vol. 12, no. 5, pp. 05024-1-05024-5, October 2020. DOI: $10.21272 /$ jnep.12(5).05024.

[40] S. Piltyay, A. Bulashenko, H. Kushnir, and O. Bulashenko, "New tunable iris-post square waveguide polarizers for satellite information systems", IEEE 2nd International Conference on Advanced Trends in Information Theory (ATIT), Kyiv, Ukraine, November 2020, pp. 342-348. DOI: 10.1109/ATIT50783.2020.9349357.

[41] S. I. Piltyay, A. V. Bulashenko, and I. V. Demchenko, "Compact polarizers for satellite information systems", IEEE International Conference on Problems of Infocommunications. Science and Technology, Kharkiv, Ukraine, October 2020, pp. 557-562. DOI: 10.1109/PICST51311.2020.9467889.

[42] A. Tribak, A. Mediavilla, J.L. Cano, M. Boussouis, and K. Cepero "Ultra-broadband low axial ratio corrugated quad-ridge polarizer", European Microwave Conference, Rome, Italy, 2009, pp.73-74. DOI: $10.23919 /$ EUMC.2009.5295927.

[43] F. F. Dubrovka, et al., "Eigenmodes of coaxial quad-ridged waveguides. Theory", Radioelectronics and Commun. Systems, vol. 57, no. 1, pp. 1-30. 2014. DOI: 10.3103/S0735272714010014.

[44] L.A. Rud, K.S. Shpachenko, "Polarizers on sections of square waveguides with inner corner ridges", IEEE VIII International Conference on Antenna Theory and Techniques, Kyiv, Ukraine, 2011. DOI: 10.1109/ICAT.2011.6170775.

[45] F. F. Dubrovka, et al., "Eigenmodes of coaxial quad-ridged waveguides. Numerical results", Radioelectron. \& Comm. Systems, vol. 57, no 2, pp. 59-69, 2014. DOI: 10.3103/S0735272714020010.

[46] A.W. Pollak, M.E. Jones, "A compact quad-ridge orthogonal mode transducer with wide operational bandwidth", IEEE Antennas and Wireless Propagation Letters, Vol. 17, no 3, pp. 422-425, 2018. DOI: 10.1109/LAWP.2018.2793465.

[47] F. F. Dubrovka, et al., "Eigenmodes of sectoral coaxial ridged waveguides", Radioelectronics and Commun. Systems, vol. 55, no. 6 , pp. 239-247. June 2012. DOI: 10.3103/S0735272712060015.

[48] S.-M. Hwang, et al., "New design method for a dual band waveguide iris polarizer", IEEE Int. Symp. on Microwave, Antenna, Propagat., and EMC Technologies for Wireless Communications, Hangzhou, China, 2007, pp. 435-438. DOI: 10.1109/MAPE.2007.4393644.

[49] H. Kushnir, et al., "Multiple reflections method for diaphragms polarizers development", IEEE International Conference on Problems of Infocommunications. Science and Technology (PIC S\&T), Kharkiv, Ukraine, 2021.

[50] F. F. Dubrovka et al., "Electrodynamics boundary problem solution for sectoral coaxial ridged waveguides by integral equation technique", Radioelectronics and Communications Systems, vol. 55, no. 5, pp. 191-203. May 2012. DOI: 10.3103/S0735272712050019.

[51] F. F. Dubrovka, et al., "Prediction of eigenmodes cutoff frequencies of sectoral coaxial ridged waveguides", XI International Conference on Modern Problems of Radio Engineering, Telecommunications and Computer Science. Lviv-Slavske, Ukraine, February 2012, pp. 191.

[52] A. Bulashenko, S. Piltyay, et al., "Mathematical modeling of iris-post sections for waveguide filters, phase shifters and polarizers", 2nd Int Conf. on Advanced Trends in Information Theory, Kyiv, Ukraine, 2020, pp. 330-336. DOI: 10.1109/ATIT50783.2020.9349321.

[53] Y. Herhil, et al., "Characteristic impedances of rectangular and circular waveguides for fundamental modes", IEEE 3rd Ukraine Conference on Electrical and Computer Engineering, Lviv, Ukraine, August 2021.

[54] A. Bulashenko, S. Piltyay, O. Bykovskyi, and O. Bulashenko, "Synthesis of waveguide diaphragm polarizers using wave matrix approach", IEEE 3rd Ukraine Conference on Electrical and Computer Engineering, Lviv, Ukraine, August 2021.

[55] A. V. Bulashenko, S. I. Piltyay, et al., "Analytical technique for iris polarizers development", IEEE Int. Conference on Problems of Infocommunications. Science and Technology, Kharkiv, Ukraine, 2020, pp. 593-598. DOI: 10.1109/PICST51311.2020.9467981. 
[56] F. F. Dubrovka, et al., "Analytical and numerical method of constructive synthesis of optimal polarizers based on three irises in square waveguide", Radioelectronics and Commun. Systems, vol. 64, no 4, pp. 204-215, 2021. DOI: 10.3103/S073527272104004X.

[57] G. Jazani, A. Pirhadi, "Design of dual-polarised (RHCP/LHCP) quad-ridged horn antenna with wideband septum polariser waveguide feed”, Microw. Antennas Propag., Vol. 12, no. 9, pp. 1541-1545, 2018. DOI: 10.1049 /iet-map.2017.0611.

[58] J.-C. Angevain, N.J.G. Fonseca, "Waveguide septum polarizer shaped with Legendre polynomials", 11th European Conference on Antennas and Propagation, Paris, Frence, 2017, pp. 2286-2290. DOI: 10.23919/EuCAP.2017.7928324

[59] F. Dubrovka, et al, "Compact X-band stepped-thickness septum polarizer", IEEE Ukrainian Microwave Week (UkrMW), Kharkiv, Ukraine, September 2020, pp. 135-138. DOI: 10.1109/UkrMW49653.2020.9252583.

[60] B. Deutschmann, A. F. Jacob, "Broadband septum polarizer with triangular common port," IEEE Transactions on Microwave Theory and Techniques, vol. 68, no. 2, pp. 693-700, 2020. DOI: 10.1109/TMTT.2019.2951138.

[61] A.V. Bulashenko, S.I. Piltyay, and I.V. Demchenko, "Optimization of a polarizer based on a square waveguide with irises", ScienceBased Technologies, Vol. 47, no 3, pp. 287-297, 2020. DOI: 10.18372/2310-5461.47.14878

[62] A. Tribak, A. Mediavilla, K. Cepero, and J.L. Cano, "Compact K/Ka 4-port feed subsystem for dual circular polarization”, European Microwave Conference, Manchester, United Kingdom, pp. 10311034, 2011. DOI: 10.23919/EuMC.2011.6101744.

[63] J.L. Cano, et al., "On the accurate full characterization of septum polarizers through simple amplitude measurements in back-to-back configuration", IEEE Trans.on Microwave Theory and Tech., vol. 69, no 1, pp. 179-188, 2021. DOI: 10.1109/TMTT.2020.3020639.

[64] E. Wang, et al., "Wideband high-gain circularly polarized antenna array on gap waveguide for $5 \mathrm{G}$ application", International Symposium on Antennas and Propagation, Xi'an, China, 2019.

[65] C. Shu, J. Wang, and X. Chen, "A wideband dual-circularpolarization horn antenna for mmWave wireless communications", IEEE Antennas and Wireless Propagation Letters, Vol. 18, no 9, pp. 1726-1730, 2019. DOI: 10.1109/LAWP.2019.2927933.

[66] A. Bulashenko, S. Piltyay, A. Polishchuk, and O. Bulashenko, "New traffic model of M2M Technology in 5G wireless sensor networks", IEEE 2nd International Conference on Advanced Trends in Information Theory, Kyiv, Ukraine, 2020, pp. 125-131. DOI: 10.1109/ATIT50783.2020.9349305.

[67] S. I. Piltyay, A. V. Bulashenko, and I. V. Demchenko, "Wireless sensor network connectivity in heterogeneous 5G mobile systems", IEEE International Conference on Problems of Infocommunications. Science and Technology, Kharkiv, Ukraine, October 2020, pp. 625630. DOI: 10.1109/PICST51311.2020.9468073.

[68] B. Feng, et al., "A compact wideband circularly polarized magnetoelectric dipole antenna array for 5G millimeter-wave applications", IEEE Transactions on Antennas and Propagation, vol. 68, no 9, pp. 6838-6843, 2020. DOI: 10.1109/TAP.2020.2980368.

[69] A. V. Bulashenko, S. I. Piltyay, and I. V. Demchenko, "Energy efficiency of the D2D direct connection system in $5 \mathrm{G}$ networks", IEEE International Conference on Problems of Infocommunications. Science and Technology (PIC S\&T), Kharkiv, Ukraine, October 2020, pp. 537-542. DOI: 10.1109/PICST51311.2020.9468035.

[70] K. Al-Amoodi, et al., "A compact substrate integrated waveguide notched-septum polarizer for $5 \mathrm{G}$ mobile devices", IEEE Antennas and Wireless Propagation Letters, Vol. 19, no 12, pp. 2517-2521, 2020. DOI: 10.1109/LAWP.2020.3038404.

[71] A.A. Kirilenko, et al., "Reflection resonances in a waveguide section with two uneven post", Telecommunications and Radio Engineering, Vol. 68, no 11, pp. 933-942, 2009.

[72] J. Roelvink, et al., "Multi-element variable-length cylindrical posts in rectuangular waveguide", IEEE Int. Microwave Symposium Digest, San Francisco, USA, 2006. DOI: 10.1109/MWSYM.2006.249573.
[73] Y. Liu, F. Li, X. Li, and H. He, "Design and optimization of wide and dual band waveguide polarizer", Global Symposium on Millimeter Waves, Nanjing, China, 2008, pp. 385-386.

[74] S. Piltyay, A. Bulashenko, H. Kushnir, and O. Bulashenko, "Information resources economy in satellite systems based on new microwave polarizers with tunable posts", Path of Science, vol. 6, no 11, pp. 5001-5010. DOI: 10.22178/pos.55-1.

[75] Q.C. Zhu, et al., "Reactance of posts in circular waveguide", IEEE Transactions on Microwave Theory and Techniques, Vol. 55, no 8, pp. 1685-1688, 2007. DOI: 10.1109/TMTT.2007.901605.

[76] O. Sushko, et al., "Symmetrically fed 1-10 GHz log-periodic dipole antenna array feed for reflector antennas", IEEE Ukrainian Microwave Week (UkrMW), Kharkiv, Ukraine, September 2020, pp. 222-225. DOI: 10.1109/UkrMW49653.2020.9252778.

[77] S.B. Sharma, V.K. Singh, R. Dey, and S. Chakrabarty, "Analysis of a post discontinuity in an oversized circular waveguide", IEEE Transactions on Microwave Theory and Techniques, Vol. 57, no 8, pp. 1989-1995, 2009. DOI: 10.1109/TMTT.2009.2025448.

[78] L.P. Mospan, et al., "Rectangular waveguide section with a pair of antipodal posts: spectral characteristics", IEEE International Conference on Antenna Theory and Techniques, Kharkiv, Ukraine, 2015. DOI: 10.1109/ICATT.2015.7136867.

[79] L. Polo-Lopez, J.L. Masa-Campos, and J.A. Ruiz-Cruz, "Design of a reconfigurable rectangular waveguide phase shifter with metallic posts", European Microwave Conference, Nuremberg, Germany, 2017. DOI: 10.23919/EuMC.2017.8231036.

[80] L. Mospan, et al., "A multi-function resonator based on an asymmetric tri-post rectangular waveguide section", IEEE European Microwave Conf. in Central Europe, Prague, Czech Republic, 2019.

[81] A. Chittora, "Periodic metallic posts loaded compact TM01-TE11 mode converter", IEEE Conference on Applied Electromagnetics, Malaysia, 2019. DOI: 10.1109/APACE47377.2019.9020921.

[82] K. Roman, et al., "Fast method for analysis of multiple H-plane cylindrical posts with multiple cylindrical inclusions in a rectangular waveguide", IEEE Microwave Theory and Tech. in Wireless Comm., Riga, Latvia, 2020. DOI: 10.1109/MTTW51045.2020.9244922.

[83] B. Subbarao, V.F. Fusco, "Compact coaxial-fed CP polarizer", IEEE Antennas and Wireless Propagation Letters, Vol. 3, pp. 145-147, 2004. DOI: 10.1109/LAWP.2004.831084.

[84] A.V. Bulashenko, S.I. Piltyay, "Equivalent microwave circuit technique for waveguide iris polarizers development", Visnyk NTUU KPI Seriia - Radiotekhnika, Radioaparatobuduvannia, Vol. 83, pp. 17-28. 2020. DOI: 10.20535/RADAP.2020.83.17-28.

[85] A. V. Bulashenko, S. I. Piltyay, and I. V. Demchenko, "Wave matrix technique for waveguide iris polarizers simulation. Theory", Journal of Nano- and Electronic Physics, vol. 12, no. 6, pp. 06026-1-060265, December 2020. DOI: 10.21272/jnep.12(6).06026.

[86] S. I. Piltyay, A. V. Bulashenko, and I. V. Demchenko, "Analytical synthesis of waveguide iris polarizers", Telecommunications and Radio Engineering, vol. 79, no. 18, pp. 1579-1597, November 2020. DOI: 10.1615/TelecomRadEng.v79.i18.10.

[87] S. Piltyay, A. Bulashenko, I. Fesyuk, and O. Bulashenko, "Comparative analysis of compact satellite polarizers based on a guide with diaphragms", Advanced Electromagnetics, Vol. 10, no. 2, p. 44-55, 2021. DOI: 10.7716/aem.v10i2.1713.

[88] L. Lewin, Theory of Waveguides. Newnes-Butterworth, London.

[89] S. Piltyay, A. Bulashenko, et al., "FDTD and FEM simulation of microwave waveguide polarizers", 2nd Int. Conf. on Advanced Trends in Information Theory, Kyiv, Ukraine, November 2020, pp. 357-363. DOI: 10.1109/ATIT50783.2020.9349339.

[90] S. Piltyay, A. Bulashenko, and Y. Herhil, "Numerical performance of FEM and FDTD methods for the simulation of waveguide polarizers", Visnyk NTUU KPI Seriia - Radiotekhnika, Radioaparatobuduvannia, Vol. 84, pp. 11-21. 2021. DOI: 10.20535/RADAP.2021.84.11-21. 